\title{
Fault Detection and Isolation of an Aircraft Turbojet Engine Using a Multi-Sensor Network and Multiple Model Approach
}

\section{Ladislav Nyulászi*, Rudolf Andoga**, Peter Butka*, Ladislav Fözö***, Radovan Kovacs***, Tomáš Moravec**}

*Department of Cybernetics and Artificial Intelligence, FEEaI, TU Košice Letná 9, 04200 Košice, Slovak Republic

**Department of Avionics, Faculty of Aeronautics, TU Košice

Rampová 7, 04121 Košice, Slovak Republic

***Department of Aviation Engineering, Faculty of Aeronautics, TU Košice

Rampová 7, 04121 Košice, Slovak Republic

e-mail: \{ladislav.nyulaszi, rudolf.andoga, peter.butka, ladislav.fozo, radovan.kovacs, tomas.moravec\} @ tuke.sk

\begin{abstract}
Modern aircraft turbojet engines represent complex systems where it is important to focus on the issues of safety, reliability, efficiency and also the reduction of maintenance costs. Continuous progress in diagnostics brings new possibilities in the implementation of progressive methods instead of traditional based on the use of hardware redundancy. The article deals with the design of the diagnostic and backup system, which uses a voting method and analytical redundancy representing computational models using experimental identification methods (polynomial models, neural networks). Part of the system is also an expert system, which is able to distinguish between engine failure and sensor error. The proposed system for jet engines was tested in laboratory conditions on a small turbojet engine iSTC-21v with positive results.
\end{abstract}

Keywords: backup; diagnostics; experimental identification; neural networks; turbojet engine; voting method

\section{Introduction}

The increase in the complexity of aircraft turbojet engines (their structure contains a greater number of elements) also leads to the increased failure probability of engine components. Consequently, any potential failure of an aircraft engine could cause even more extensive damages, therefore the issue of safety and reliability 
come to the fore. It is essential to detect faults as fast as possible and to ensure that they do not affect the control of nonlinear systems [1,2,3], especially systems like aircraft engines, where failures can be disastrous [4, 5]. Advances in diagnostic systems offer better opportunities for the use of new progressive methods [6,7]. Today's computers can process back-up controllers and sensor models to create a highly redundant multi-sensor networks with greatly increased efficiency and reliability $[8,9]$.

Fault detection and isolation (FDI) $[10,11]$ plays a fundamental role in reducing the maintenance and operating costs and ensuring reliability and safety operation of any system, including a jet engine. A traditional approach to FDI is a hardware redundancy method that is based on the use of multiple sensors. However, this method requires additional equipment which increases cost and weight. That's why we are using analytical redundancy, which uses existing relationships between engine's parameters, so there are no need for extra hardware.

The article deals with the proposal, creation and application of the diagnosticbackup system for small turbojet engines in the software environment MATLAB/Simulink and LabView. The primary focus is oriented on real-time diagnostics of the sensors and engine components using a multi-sensor network [12] and multiple model approach. A voting method, based on results of pair comparison, detects a fault and an expert system determines the type of the fault. The system is able to detect any sensor errors during the engine's operation and to eliminate these errors with the calculated models using other sensors as the backup. These models are created by methods of experimental identification that require the existence of the studied object [13]. In our case, the real object is represented by the small turbojet engine iSTC-21v (see Fig. 1), which undergoes tests in the Laboratory of Intelligent Control Systems of Aircraft Engines [14]. The advantage of using this engine lays mainly in the relatively lower technical complexity compared to normal sized jet engines. But at the same time, the thermodynamic processes ongoing in small and standard jet engines are very similar and the proposed methods are applicable to other types of aircraft engines and systems.

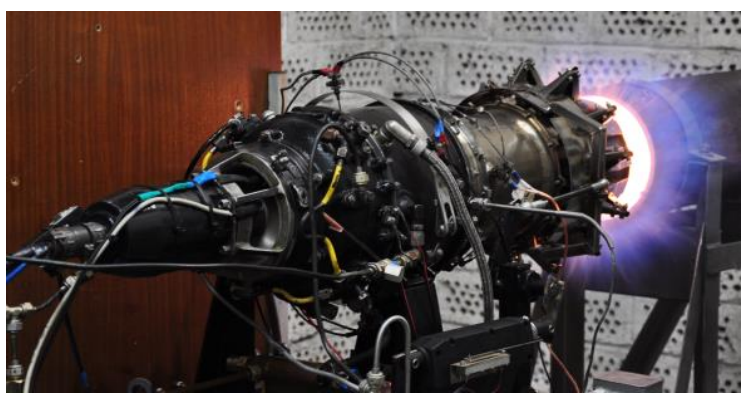

Figure 1

Small turbojet engine iSTC-21v 


\section{Related Work}

The current diagnostic systems that represent a complex of different and unrelated technologies provide only a basic level of monitoring [15]. These systems have limited capabilities and use the obtained information mainly to start maintenance actions, not for decision-making in real time. A lot of promising techniques in the field of fault detection and isolation with good results in simulation environment have been published. Some of them are mentioned in this paper, divided according to the applied methods, together with their limitations, which we try to overcome with our proposed system.

\subsection{Kalman Filters}

Merrill, Delaat and Bruton in [16] used a bank of Kalman filters (KF) for aircraft engine sensor fault detection and isolation (FDI). They successfully improved the control loop tolerance to the failure of sensors, but did not take the actuator failures into account. Kobayashi and Simon in [17] devised an aircraft engine sensor and actuator FDI system that utilizes a bank of Kalman filters. Based on the results, the designed system is promising for detection of sensor and component faults. Wei and Yingqing in [18] used KF for estimation of engine's health degradation and further fault detection. According to Zedda and Singh [19], the main disadvantages are that Kalman Filters may become unstable if computer calculations have not been sufficiently accurate or include too many small values.

\subsection{Linear/Non-Linear Gas Path Analysis}

Urban and Volponi in [20] introduced the Gas Path Analysis (GPA) as a method for determining the condition of engine components by using existing aerothermodynamic relationships between the measured gas path parameters and components. Linear GPA works with the assumption that there are only small changes in health parameters and influence/coefficient matrix (ICM) is invertible. According to Escher in [21] this method does not deal with sensor noise and requires many measurements for the analysis. Escher uses the Newton-Raphson technique to solve the non-linear relationship between the health-parameters and measurements.

\subsection{Bayesian Belief Network}

Breese et al. in [22] presented a Bayesian Belief Network (BBN) method that uses the statistical data of the engine, for detection of faults on large gas turbines. Romessis and Mathioudakis in [23] introduced a diagnostic BBN that is based on a heuristic approach for determining the network elements. It can be implemented 
on any type of engine, but it requires scarce statistical data and BBNs cannot deal with sensor bias.

\subsection{Genetic Algorithms}

Zedda and Singh in [19] proposed a diagnostic method based on a genetic algorithm (GA). It is used to gain a set of engine parameters which produce a set of predicted dependent parameters through a non-linear model of the gas turbine. The disadvantages are that the method is more computationally demanding than the classic estimation techniques and it is limited to four parameters experiencing parallel degradation. These limitations have been overcome by improving the methods. Kobayashi and Simon in [24] devised the hybrid diagnostic technique that consists of Neural Networks used to estimate the engine internal health and Genetic Algorithms for sensor bias detection and estimation.

\section{Experimental Identification}

Identification represents the process leading to the compilation of a mathematical model of a certain system by using measured data. We used the measured engine data and experimental identification methods to calculate coefficients and the parameters of the engine's mathematical models.

The basic concepts of the system experimental identification are a real object and its model. A real object represents the original device, in our case the engine iSTC$21 \mathrm{v}$, on which, we can execute certain measurements, to gain knowledge about the systems parametric relationships. System validation is performed through model simulation and the subsequent comparison of each output (measured outputs of a real object are compared with outputs calculated by the model). The process runs until the required similarity of the model, with the real object, is reached $[25,26$, 27].

In recent years, there has been substantial progress in the area of experimental identification methods. For these methods, it is essential to have a studied object and the possibility to do experiments with it, but they do not require precise knowledge of the system structure and the description of ongoing processes. To create models of the iSTC-21v engine's parameters, we have chosen 7 methods of experimental identification, which are:

1) Polynomial models
a. ARX
b. ARMAX
c. Output - Error
d. Box - Jenkins 
2) Artificial Neural Networks

a. Time Delay Neural Network

b. Distributed Delay Neural Network

c. NARX Network

\subsection{Polynomial Models}

\subsubsection{ARX Model}

ARX model (Auto-Regressive model with eXternal input) [28] estimates parameters using the least squares method provided the measured value is affected only by white noise. It is considered as a simple and highly usable method. ARX model is represented as an equation:

$y(t)+a_{1} y(t-1)+\ldots+a_{n_{a}} y\left(t-n_{a}\right)=b_{1} u(t-1)+b_{n_{b}} u\left(t-n_{k}-n_{b}+1\right)+e(t)$,

where

$y(t)$ is the system output and $t$ is time

$a_{1} \ldots a_{n}$ and $b_{1} \ldots b_{n}$ are model parameters for data estimation

$n_{a}$ is the order of the polynomial $A(q)$

$n_{b}$ is the order of the polynomial $B(q)$

$n_{k}$ is the time delay between input $\mathrm{u}(t)$ and output $y(t)$

$y(t-1) \ldots y\left(t-n_{a}\right)$ are previous outputs that depend on current outputs

$u(t-1) \ldots u\left(t-n_{k}-n_{b}+1\right)$ are previous inputs that depend on current inputs

$e(t)$ is white noise

ARX model can also be represented by a more compact form:

$A(q) y(t)=B(q) u\left(t-n_{k}\right)+e(t)$,

where

$A(q)=1+a_{1} q^{-1}+\ldots+a_{n_{a}} q^{-n_{a}}$,

$B(q)=b_{1}+b_{2} q^{-1}+\ldots+b_{n_{b}} q^{-n_{b}+1}$,

and $q^{-1}$ is the delay operator defined as:

$q^{-1} u(t)=u(t-1)$.

The ARX model architecture is shown in Fig. 2. 


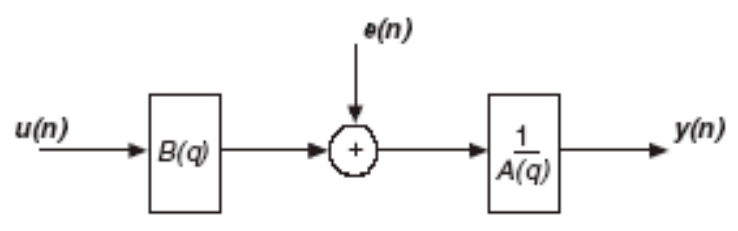

Figure 2

The architecture of the ARX model [29]

\subsubsection{ARMAX Model}

ARMAX model (Auto-Regressive Moving Average model with eXternal input) [29] is used to estimate parameters by means of the recursive extended least square method. It is able to model stochastic and deterministic parts of the system independently and describes the dynamic behavior of the disturbance variables. The outcome of the ARMAX model is expressed through the idpoly object. This model is defined by an equation:

$$
A(q) y(t)=B(q) u(t)+C(q) e(t)
$$

where

$$
C(q)=1+c_{1} q^{-1}+\ldots+c_{n_{c}} q^{-n_{c}}
$$

The structure of the ARMAX model can be seen in Fig. 3.

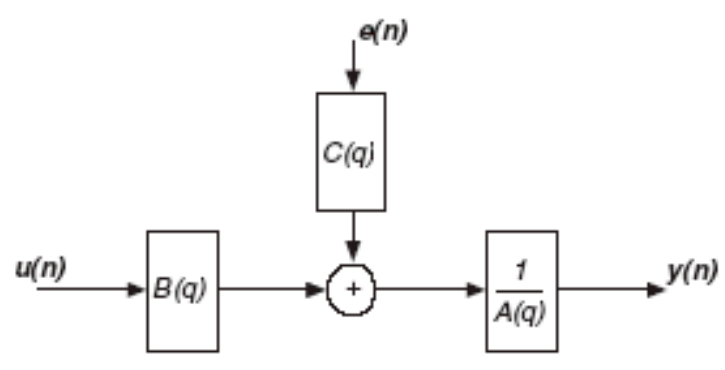

Figure 3

The scheme of the ARMAX model [29]

\subsubsection{Output - Error Model}

Output - Error (OE) model [30] describes the system dynamics separately from the stochastic dynamics. It does not use any parameters in order to simulate the disturbance characteristics. As the identification method of the OE model is used the prediction error method. This model is defined by an equation: 
$y(t)=\frac{B(q)}{F(q)} u\left(t-n_{k}\right)+e(t)$

where

$F(q)=1+f_{1} q^{-1}+\ldots+f_{n_{f}} q^{-n_{f}}$,

The structure of the OE model can be seen in Fig. 4.

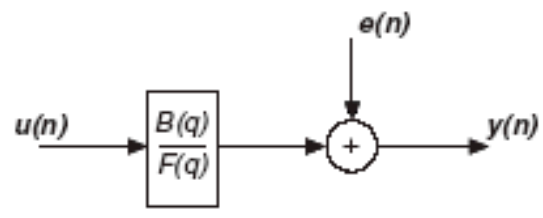

Figure 4

Output - Error model architecture [29]

\subsubsection{Box - Jenkins Model}

Box - Jenkins (BJ) model [29] is a mathematical model used to predict data within a time series. It is the combination of AR and MA models, where failures are modeled separately from the dynamics of the system:

$y(t)=\frac{B(q)}{F(q)} u\left(t-n_{k}\right)+\frac{C(q)}{D(q)} e(t)$,

where

$$
D(q)=1+d_{1} q^{-1}+\ldots+d_{n_{d}} q^{-n_{d}},
$$

The scheme of the Box - Jenkins model is shown in Fig. 5.

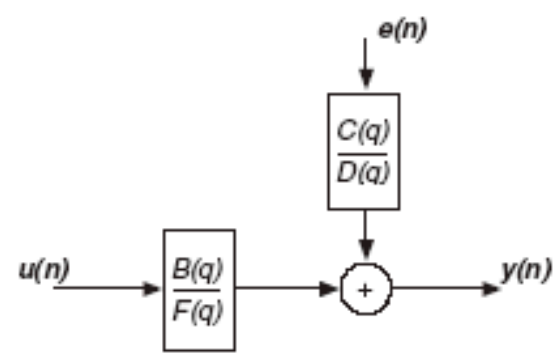

Figure 5

The structure of the Box - Jenkins model [29] 


\subsection{Artificial Neural Networks}

\subsubsection{Time Delay Neural Network}

Time delay neural networks (TDNNs) [31, 32] represents an architecture which main purpose is to work on sequential data. Their units generally form part of a larger pattern recognition system and are able to recognize characteristics independent of time-shift. A key ability of the TDNNs is to express a relation between inputs in time and so on recognizing patterns between the delayed inputs.

\subsubsection{Distributed Delay Neural Network}

Distributed delay neural networks (DDNNs) [33] are similar to feed forward networks, with the exception that each input and layer weights have a tap delay line associated with it. This allows the network to have a finite dynamic response to time series input data. This network is also close to the TDNN, with the difference that it only has delays on the input weight.

\subsubsection{NARX Neural Network}

NARX (Nonlinear Autoregressive models with eXogenous input) neural network [34] is capable of predicting one time series, given past values of the same time series and current and past values of the exogenous or external time series. In addition, the model contains an "error" term, which applies to the fact that knowledge of the other concepts will not enable the present value of the time series to be predicted precisely.

\section{Diagnostic and Backup System}

The proposed diagnostic and backup architecture is composed of two main blocks. The diagnostic block created in the LabView environment consists of the diagnostic method (voting method) to detect an error and the expert system to determine the type of the error. The backup block contains the calculated mathematical models, obtained by experimental identification methods, in MATLAB/Simulink. Both are interconnected and communicate through the shared variables using OPC server and fully described in this chapter. 


\subsection{Multi-Sensor Network}

Experimental identification [26] is the process that leads to the calculation of the mathematical model of a real system using data obtained by measurement. In our case, these data are represented by ten parameters of the small turbojet engine iSTC-21v. These parameters are:

- $\quad \mathrm{T}_{2 \mathrm{C}}$ - total temperature on the compressor's outlet $\left[{ }^{\circ} \mathrm{C}\right]$

- $\mathrm{T}_{3 \mathrm{C}}$ - total temperature in the combustion chamber $\left[{ }^{\circ} \mathrm{C}\right]$

- $\mathrm{T}_{4 \mathrm{C}}-$ total temperature beyond the gas turbine $\left[{ }^{\circ} \mathrm{C}\right]$

- $\quad \mathrm{P}_{2 \mathrm{C}}-$ total pressure of air beyond the compressor $[\mathrm{Pa}]$

- $\mathrm{P}_{3 \mathrm{C}}$ - total pressure of gas at the inlet to the gas turbine [Pa]

- $\quad \mathrm{P}_{\mathrm{pal}}-$ fuel pressure $[\mathrm{Pa}]$

- $\mathrm{Q}_{\mathrm{pal}}$ - fuel flow supply [1/min]

- $\mathrm{F}_{\mathrm{t}}$ - thrust of the engine $[\mathrm{N}]$,

- $\mathrm{n}$ - speed of the turbo-compressor [rpm]

- $\mathrm{A}_{5}$ - exhaust nozzle diameter [\%]

The measured data was divided into training, testing and validation sets. In order to get the most accurate experimental models, we have created over 5000 models in the MATLAB/Simulink environment, using the above mentioned experimental identification methods in different configurations. Then we compared these models, using validation data and selected the best one, based on the values of the mean absolute percentage error (MAPE). The results are shown in Table 1. The simplified structure of the multi-sensor network can be seen in Fig. 6. Each of the inputs to individual models of one parameter is measured by different sensor except exhaust nozzle diameter $A_{5}$ which is the essential model input because it influences the thermodynamic properties of the engine and this eliminates the possibility of mutual influence and thus increases the reliability and efficiency of the system. 


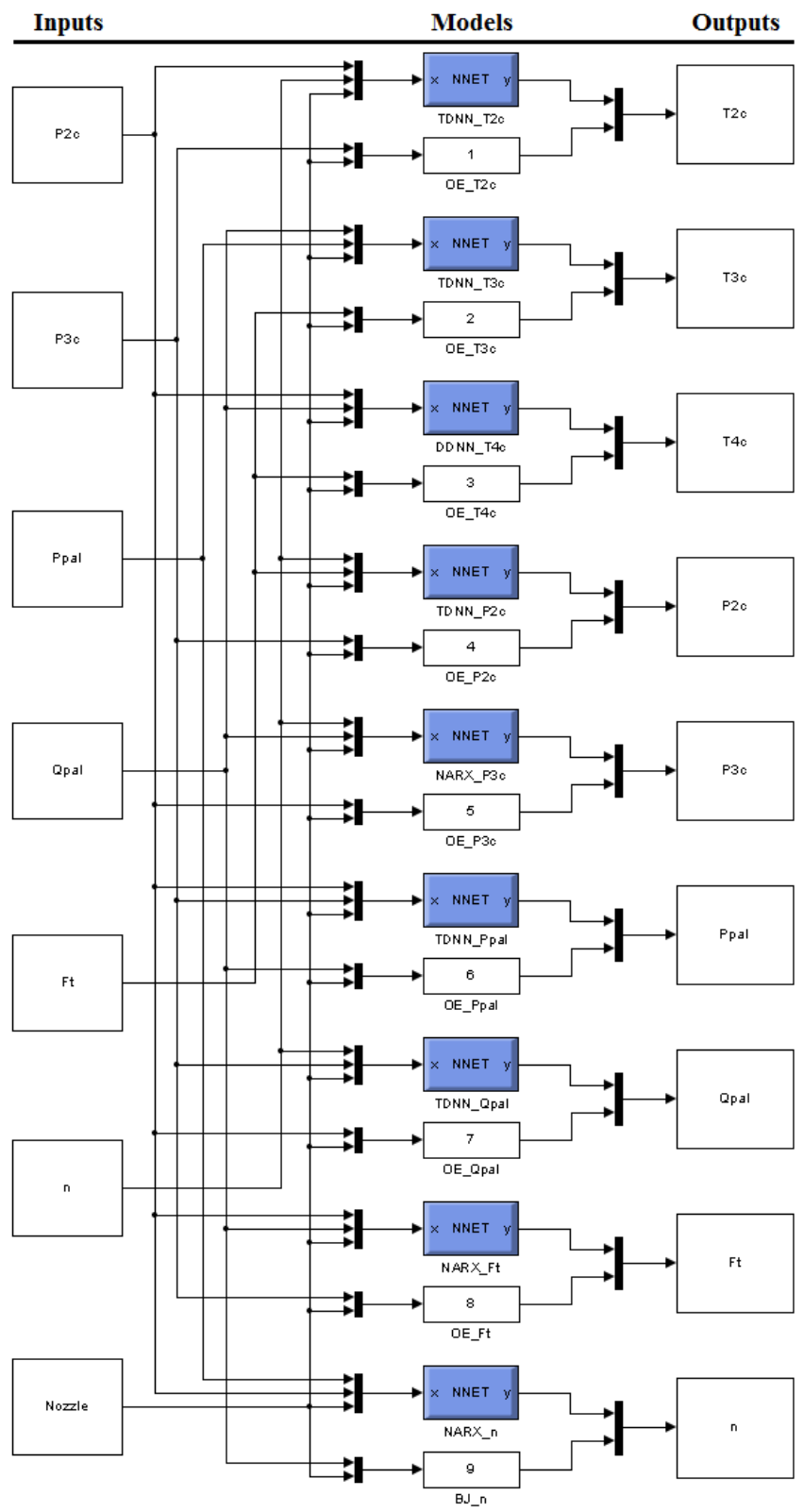

Figure 6

The scheme of multi-sensor network 
Table 1

Final experimental models of engine parameters

\begin{tabular}{|c|c|c|c|}
\hline Outputs & Inputs & Method & MAPE [\%] \\
\hline \multirow{2}{*}{$\mathrm{T}_{2 \mathrm{C}}$} & $\mathrm{P}_{2 \mathrm{C}}, \mathrm{n}, \mathrm{A}_{5}$ & TDNN & 7.9784 \\
\cline { 2 - 4 } & $\mathrm{P}_{3 \mathrm{C}}, \mathrm{A}_{5}$ & Output - Error & 5.1810 \\
\hline \multirow{2}{*}{$\mathrm{T}_{3 \mathrm{C}}$} & $\mathrm{Q}_{\mathrm{pal}}, \mathrm{P}_{\mathrm{pal}}, \mathrm{A}_{5}$ & TDNN & 1.8654 \\
\cline { 2 - 4 } & $\mathrm{F}_{\mathrm{t}}, \mathrm{A}_{5}$ & Output - Error & 4.0667 \\
\hline \multirow{2}{*}{$\mathrm{T}_{4 \mathrm{C}}$} & $\mathrm{P}_{2 \mathrm{C}}, \mathrm{Q}_{\mathrm{pal}}, \mathrm{A}_{5}$ & DDNN & 5.1094 \\
\cline { 2 - 4 } & $\mathrm{F}_{\mathrm{t}}, \mathrm{A}_{5}$ & Output - Error & 4.4707 \\
\hline \multirow{2}{*}{$\mathrm{P}_{2 \mathrm{C}}$} & $\mathrm{n}, \mathrm{F}_{\mathrm{t}}, \mathrm{A}_{5}$ & TDNN & 1.1303 \\
\cline { 2 - 4 } & $\mathrm{P}_{3 \mathrm{C}}, \mathrm{A}_{5}$ & Output - Error & 3.2630 \\
\hline \multirow{2}{*}{$\mathrm{P}_{3 \mathrm{C}}$} & $\mathrm{n}, \mathrm{Q}_{\mathrm{pal}}, \mathrm{A}_{5}$ & NARX & 0.8733 \\
\cline { 2 - 4 } & $\mathrm{P}_{2 \mathrm{C}}, \mathrm{A}_{5}$ & Output - Error & 2.7789 \\
\hline \multirow{2}{*}{$\mathrm{P}_{\mathrm{pal}}$} & $\mathrm{P}_{2 \mathrm{C}}, \mathrm{P}_{3 \mathrm{C}}, \mathrm{A}_{5}$ & TDNN & 4.8581 \\
\cline { 2 - 4 } & $\mathrm{Q}_{\mathrm{pal}}, \mathrm{A}_{5}$ & Output - Error & 10.2502 \\
\hline \multirow{2}{*}{$\mathrm{Q}_{\mathrm{pal}}$} & $\mathrm{n}, \mathrm{P}_{3 \mathrm{C}}, \mathrm{A}_{5}$ & TDNN & 2.0113 \\
\cline { 2 - 4 } & $\mathrm{P}_{2 \mathrm{C}}, \mathrm{A}_{5}$ & Output - Error & 7.5757 \\
\hline \multirow{2}{*}{$\mathrm{F}_{\mathrm{t}}$} & $\mathrm{P}_{2 \mathrm{C}}, \mathrm{Q}_{\mathrm{pal}}, \mathrm{A}_{5}$ & NARX & 5.7475 \\
\cline { 2 - 4 } & $\mathrm{P}_{3 \mathrm{C}}, \mathrm{A}_{5}$ & Output - Error & 8.0302 \\
\hline \multirow{2}{*}{$\mathrm{n}$} & $\mathrm{P}_{\mathrm{pal}}, \mathrm{P}_{2 \mathrm{C}}, \mathrm{A}_{5}$ & NARX & 0.6436 \\
\cline { 2 - 4 } & $\mathrm{Q}_{\mathrm{pal}}, \mathrm{A}_{5}$ & Box - Jenkins & 2.2926 \\
\hline
\end{tabular}

\subsection{Diagnostic Modules}

The complete diagnostic and backup system is composed of nine diagnostic modules for each of the chosen iSTC-21v engine's parameters. These modules in monitor engine condition in real time and evaluate whether the sensors provide correct data. If a sensor fault is detected, they can replace it with backup represented by the created experimental model of that parameter whose sensor is faulty. Due to the limited number of pages, for example, the designed architecture of diagnostic module for parameter $n$ (speed of the turbo-compressor) is shown in the Fig. 7. 


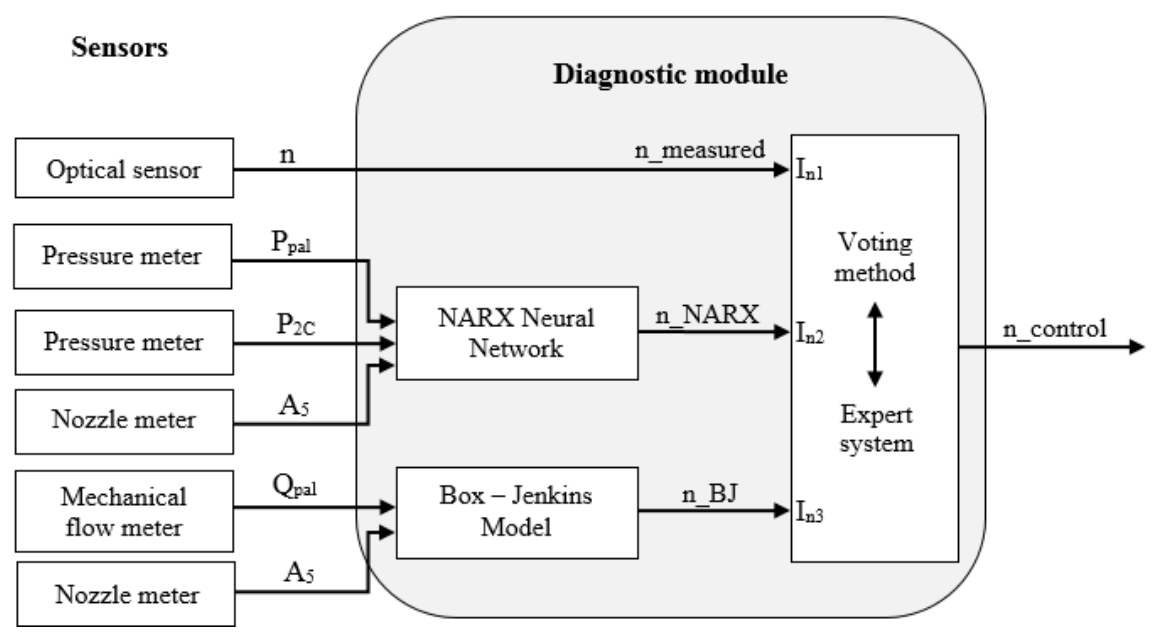

Figure 7

The structure of the diagnostic module for the parameter $n$

The system is based on triple modular redundancy and a dynamic backup which switches between basic and backup elements, depending on the results of the diagnostics. As a diagnostic method the voting method was selected [35, 36]. Inputs to the voting method are the measured data from the sensor and modeled values of parameter computed by experimental models. In our case, for parameter $n$ this represents a signal from the optical sensor $\left(I_{n l}\right)$ and outputs of the NARX neural network $\left(I_{n 2}\right)$ and Box - Jenkins model $\left(I_{n 3}\right)$. These inputs are fed into the block of pair comparisons, where each couple is compared and evaluated depending on the amount of the maximum allowed deviation. The size of this permissible error for each pair is computed as the sum of the allowed deviation values for signals that make up the pair. For the sensors it represents the accuracy with which they work and for experimental models that value is determined as the maximum absolute error (MaxAE), compared to real measured data. The maximum allowed deviation values for parameter $n$ are shown in Table 2.

Table 2

Maximum permissible error of inputs

\begin{tabular}{|c|c|c|c|}
\hline Inputs & $\begin{array}{c}\text { Allowed } \\
\text { deviation [rpm] }\end{array}$ & Pair comparison & $\begin{array}{c}\text { Sum of allowed } \\
\text { deviation [rpm] }\end{array}$ \\
\hline $\mathrm{I}_{\mathrm{n} 1}$ & 200 & $\mathrm{I}_{\mathrm{n} 1}$ and $\mathrm{I}_{\mathrm{n} 2}$ & 1252 \\
\hline $\mathrm{I}_{\mathrm{n} 2}$ & 1052 & $\mathrm{I}_{\mathrm{n} 1}$ and $\mathrm{I}_{\mathrm{n} 3}$ & 3363 \\
\hline $\mathrm{I}_{\mathrm{n} 3}$ & 3163 & $\mathrm{I}_{\mathrm{n} 2}$ and $\mathrm{I}_{\mathrm{n} 3}$ & 4215 \\
\hline
\end{tabular}

If two out of the three compared output pairs exceed the sum of the permissible error, then the output parameter, which is present in both of the error exceeding pairs, is declared as faulty. If all three pairs exceed the maximum deviation value, 
the system verifies inputs to the models. In the case where the diagnostic/backup system evaluates data from these sensors as accurate, the output of the model is set as correct.

\subsection{Expert System}

When a fault is detected, the right decision about its type (sensor, actuator or component) is essential. Several methods have been suggested in this area, but most of them were mathematical calculations [37] or were not tested on a real system, only in a simulation environment [38].

We have proposed an effective and low computer resource demanding method to distinguish between a sensor error and a component/engine fault. Due to the complexity of this area, it is difficult and almost impossible to have a hundred percent success, in determining the exact type of failure. So the system always chooses the option with a higher probability. A real-time expert system provides immediate decisions using if-then rules in its knowledge base [39]. This base can contain many rules for all engine sensors, but we could summarize them into three basic rules:

- If only one sensor provides incorrect data, then it is a sensor fault (SF). This is based on the assumption that an engine fault has an influence on more than just one parameter.

$$
\text { IF } \sum_{i=1}^{9} E_{i}=1 \text { THEN }(\mathrm{SF}=1 \text { AND EF }=0)
$$

- If two sensors provide incorrect data, then it is a sensor fault / engine fault. - It depends on exactly which sensors the voting method has evaluated as a fault. If they can be affected by one interference (sensor fault) or if damage to one engine component can affect the values of only these two sensors (component fault).

$$
\text { IF } \sum_{i=1}^{9} E_{i}=2 \text { THEN }(\mathrm{SF}=1 \text { OR EF }=1)
$$

- If three or more sensors provide incorrect data, then it is an engine fault (EF). - This is determined by the fact that the probability of failure of the three and more sensors is very small.

$$
\text { IF } \sum_{i=1}^{9} E_{i} \in\langle 3,9\rangle \text { THEN (SF = } 0 \text { AND EF = 1) }
$$

In the case of fault detection, the results of the voting method $E_{i}$ are transferred to the expert system. It determines whether a sensor or engine fault is detected. If it is a sensor fault, the output of the diagnostic/backup system is represented by the 
most accurate signal (based on the allowed deviation value - see Table 2) which was diagnosed by the voting method as correct. If it is an engine fault, the output of the diagnostic and backup system is set as the signal from the sensor, not the model, so we get the real measured values. Moreover, this signal can be used to parameterize the situational control system and choose appropriate control strategy to handle an engine failure (e.g. overheat). The designed decision making rules of the expert system are simple probability based options and therefore robust, thus not susceptible to changes in sensor network or modifications in the measured parameters. A more complex expert system with further decision making when rules two and three are active can be designed to more precisely evaluate the failure of the engine as well as evaluate the probability of the classification. The link scheme is shown in Fig. 8.

\section{Diagnostic and Backup System}

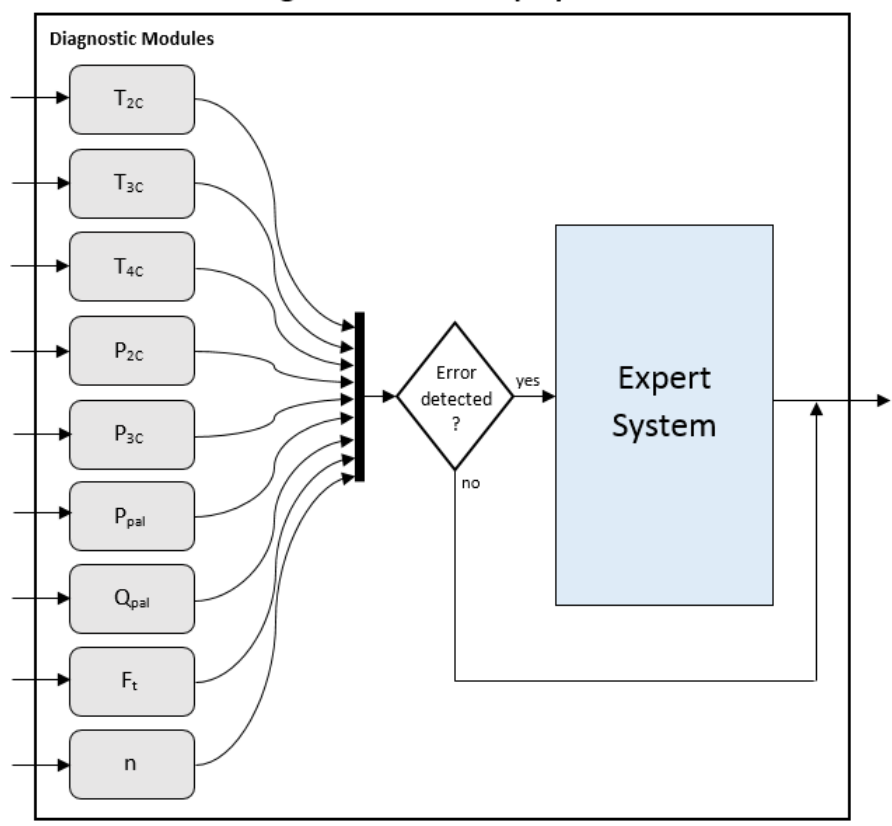

Figure 8

Connection diagram of individual parts of the diagnostic and backup system

\section{System Test Results}

The functionality of the proposed and implemented system for real-time diagnostics and backup has been tested in the Laboratory of intelligent control systems of jet engines on the small turbojet engine iSTC-21v. The first test 
represents a faultless engine operation and the results for the speed of the turbocompressor $n$, is shown in Fig. 9. The engine was run for 80 seconds and the graph shows the measured data from the optical sensor (blue) and approximate data of the parameter calculated by NARX neural network (red) and Box - Jenkins model (black). The output of the diagnostic/backup system (green) is the most accurate signal, which in the case of faultless operation of the engine represents a signal from the optical sensor. During the test, the mean absolute error of the NARX neural network was MAE $=262.2621 \mathrm{rpm}$ and error of the Box - Jenkins model was MAE $=945.7668 \mathrm{rpm}$.

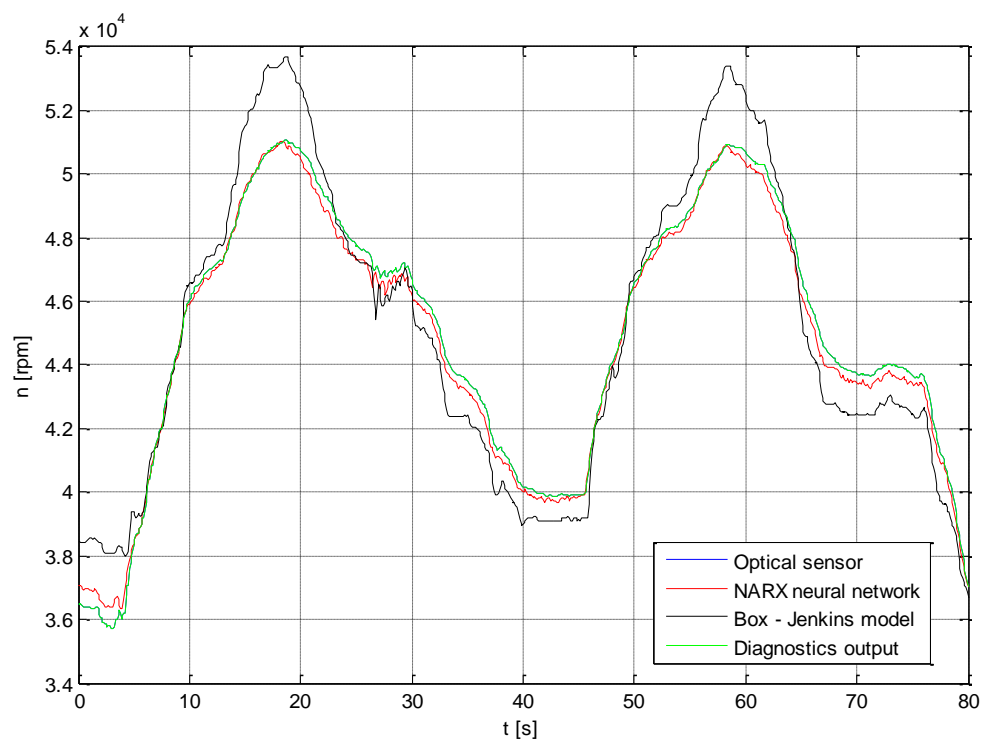

Figure 9

Test of the system for parameter $n$ during faultless engine operation

For complete testing of the system response, experiments were also performed when a fault occurs. Two types of sensor errors that are the most common were considered:

- Failure of individual inputs - caused by sudden power loss or loss of the communication channel

- Presence of random input values - caused by electromagnetic interference (noise)

As the sensors cannot be physically damaged, the errors were simulated by influencing input values of the system. 


\section{Testing for Failure of Individual Inputs}

Failure of individual inputs is represented by a sudden fall of the measured data to zero. This fault was simulated in such a way that at the specific intervals, the real value of the chosen input (signal from the sensor) was set to zero. To generate an error, in the $20^{\text {th }}$ second was measured data from optical sensor (parameter $n$ ) set to zero. The implemented system diagnosed the sensor error and replaced it with the backup which is the output of the NARX neural network. In the $40^{\text {th }}$ second was the value of the parameter $P_{p a l}$ changed to zero, which affected the accuracy of the neural model and thus simulated an error. Only by the pair comparison results, it was impossible to determine which input $\left(I_{n 1}, I_{n 2}, I_{n 3}\right)$ is wrong. So the system checked all sensors and model outputs and diagnosed that only the Box Jenkins model provided correct data. In the $60^{\text {th }}$ second were all data set back to the real values and the diagnostics output was again the most accurate signal from optical sensor. As can be seen in Fig. 10, the designed diagnostic and backup system was able to detect failures and replace them with the backup (data acquired by experimental models).

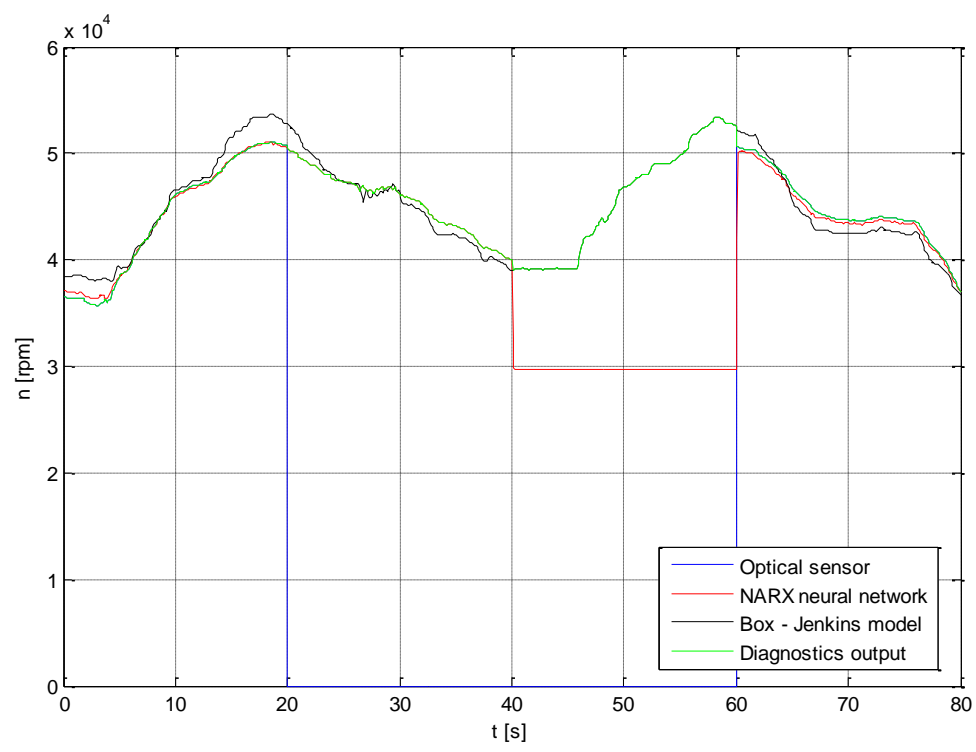

Figure 10

Test of the system for failure of individual inputs

\section{Discrimination Engine/Sensor Failure Test}

In this experiment, we tested the ability of the system to distinguish between engine and sensor faults by adding random input values, thus simulating additive errors. The random values appear as a rapid increase or decrease in the size of inputs of the voting method over their real-actual values. It was simulated by adding a certain value to the real values of individual inputs at a certain time. 
The response of the system is shown in Fig. 11. Similar to the previous test, the error of the optical sensor was first simulated by adding the speed of $10000 \mathrm{rpm}$ $\left(20^{\text {th }}-80^{\text {th }}\right.$ second $)$. The neural model error was then generated by increasing the value of fuel pressure $P_{p a l}$ of $30 \mathrm{~Pa}\left(40^{\text {th }}-80^{\text {th }}\right.$ second $)$. In both cases, the system correctly detected the sensor failure and replaced it with a backup. Unlike the previous test, the adjusted values were not returned to true values. In the $60^{\text {th }}$ second $0.51 / \mathrm{min}$ to the real value of the fuel flow supply $Q_{p a l}$ was added. It caused that the expert system diagnosed engine fault because more than two sensors provided the incorrect data and the signal from optical sensor was set as the diagnostic output. This test shows than the implemented diagnostic/backup system is capable of responding to errors caused by random input values and engine faults.

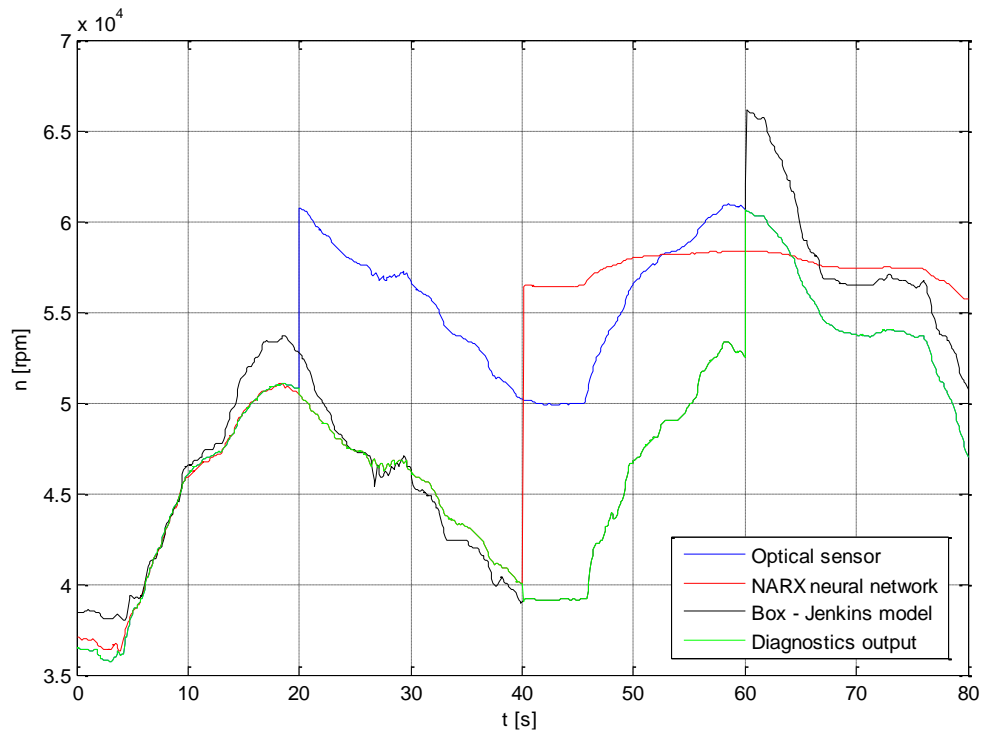

Figure 11

Test of the system for random input values

\section{Conclusions}

The issues described in this paper represent the essential components for on-line diagnostics of aircraft turbojet engines. It is made important by the fact, that all aviation systems have to work, without failure, because even a minor failure can have catastrophic consequences. We have designed a diagnostic and backup system using a multi-sensor network and multiple model approach for fault detection and isolation. It utilizes the signals from sensors and approximate values of parameters obtained by polynomial models and neural networks. Using these models as backups, leads to increased redundancy of the system without adding additional sensors, resulting in a cost reduction. The functionality and reliability of 
the system was successfully tested on the small turbojet engine, iSTC-21v, under laboratory conditions. The main advantage of the proposed system is the ability to diagnose faults, distinguish between sensor errors and engine faults using the expert system and also to prevent sensor errors that have an impact on engine operation and by timely application of the designed backups. The system can be improved in the future by adding more rules to the expert system, so it will provide more accurate information about the detected faults of the diagnosed object.

\section{Acknowledgement}

This work was supported by KEGA under Grant No. 014TUKE-4/2015 "Digitalization, virtualization and testing of a small turbojet engine and its elements using stands for modern applied lecturing".

\section{References}

[1] H. K. Lam, F. H. F. Leung, P. K. S. Tam, "Stable and robust fuzzy control for uncertain nonlinear systems," IEEE Transactions on Systems, Man and Cybernetics, Part A: Systems and Humans, Vol. 30, No. 6, 2000, pp. 825840

[2] M.-L. Tomescu, S. Preitl, R.-E. Precup, J. K. Tar, "Stability analysis method for fuzzy control systems dedicated controlling nonlinear processes," Acta Polytechnica Hungarica, Vol. 4, No. 3, 2007, pp. 127-141, ISSN $1785-8860$

[3] J. K. Tar, J. F. Bitó, I. J. Rudas, "Contradiction Resolution in the Adaptive Control of Underactuated Mechanical Systems Evading the Framework of Optimal Controllers," Acta Polytechnica Hungarica, Vol. 13, No. 1, 2016, pp. 97-121, ISSN 1785-8860

[4] R. Isermann, "Fault-Diagnosis Systems: An Introduction from Fault Detection to Fault Tolerance," Springer - Verlag Berlin Heidelberg, 2006, 475 pp., ISBN 3-540-24112-4

[5] L. Nyulászi, "Improving the Diagnostic and Backup System Using Experimental Identification Methods," in SCYR 2016: Proceedings from conference: $16^{\text {th }}$ Scientic Conference of Young Researchers, 2016, pp. 148149, ISBN 978-80-553-2566-8

[6] A. Linke-Diesinger, "Systems od Commercial Turbofan Engines: An Introducion to Systems Functions," Springer - Verlag Berlin Heidelberg, 2008, 239 pp., ISBN 978-3-540-73619-6

[7] J. S. Guan, L. Y. Lin, G. L. Ji, Ch. M. Lin, T. L. Le, I. J. Rudas, "Breast tumor computer-aided diagnosis using self-validating cerebellar model neural networks," Acta Polytechnica Hungarica, Vol. 13, No. 4, 2016, pp. 39-52, ISSN 1785-8860 
[8] J. B. Armstrong, D. L. Simon, "Implementation of an Integrated On-Board Aircraft Diagnostic System,” NASA/TM-2012-217279, AIAA-2011-5859, 2012

[9] M. Laššák, K. Draganová, "Improvement of low-cost MEMS gyroscope characteristics by data filtering and fusion", Advances in Military Technology, Vol. 11, No. 2, 2016, pp. 171-178, DOI: 10.3849/aimt.01126

[10] N. Meskin, K. Khorasani, "Fault Detection and Isolation: Multi-Vehicle Unmanned Systems," Springer - Verlag New York, 2011, 166 pp., ISBN 978-1-4419-8392-3

[11] J. Bokor, Z. Szabó, "Fault detection and isolation in nonlinear systems," in Annual Reviews in Control, Vol. 33, Issue 2, Elsevier, 2009, pp. 113-123, ISSN 1367-5788

[12] Y. Mon, Ch. Lin, I. J. Rudas, "Wireless Sensor Network (WSN) Control for Indoor Temperature Monitoring," Acta Polytechnica Hungarica, Vol. 9, No. 7, 2012, ISSN 1785-8860

[13] L. Nyulászi, L. Madarász, "Experimental Identification of the Small Turbojet Engine MPM-20," in CINTI 2014, 2014, pp. 497-501, ISBN 9781-4799-5338-7

[14] L. Fözo, et al., "Description of an intelligent small turbo-compresor engine with variable exhaust nozzle," in SAMI 2015: 13 ${ }^{\text {th }}$ IEEE International Symposium on Applied Machine Intelligence and Informatics, 2015, pp. 157-160, ISBN 978-1-4799-8220-2

[15] J. S. Litt, et al., "A Survey of Intelligent Control and Health Management Technologies for Aircraft Propulsion Systems," NASA/TM-2005-213622, ARL-TR-34 13, 2005

[16] W. C. Merrill, J. C. Delaat, W. M. Bruton, "Advanced detection, isolation, and accommodation of sensor failures - Real-time evaluation," Journal of Guidance, Control, and Dynamics, Vol. 11, No. 6, 1988, pp. 517-526, ISSN 0731-5090

[17] T. Kobayashi, D. L. Simon, "Evaluation of an Enhanced Bank of Kalman Filters for In-Flight Aircraft Engine Sensor Fault Diagnostics," NASA/TM2004-213203, ARL-TR-3252, 2004

[18] X. Wei, G. Yingqing, "Aircraft Engine Sensor Fault Diagnostics Based on Estimation of Engine's Health Degradation," Chinese Journal of Aeronautics, Vol. 22, No. 1, 2009, pp. 18-21, ISSN 1000-9361

[19] M. Zedda, R. Singh, "Gas turbine engine and sensor fault-diagnosis using optimisation techniques," Journal of Propulsion \& Power, Vol. 18, No. 5, pp. 1019-1025, 2002 
[20] L. Urban, A. Volponi, "Mathematical methods of relative engine performance diagnostics," SAE 1992 Transactions Journals of Aerospace, Section 1, Vol. 101, SAE Technical Paper No. 922048, 1992

[21] P. C. Escher, "Pythia: An object-oriented gas-path analysis computer program for general applications," $\mathrm{PhD}$ thesis, School of Mechanical Engineering, Cranfield University; 1995

[22] J. S. Breese, et al., "Automated Decision-Analytic Diagnosis of Thermal Performance in Gas Turbines," in Proceedings of the ASME International Gas Turbine and Aeroengine Congress and Exposition, Cologne, Germany, 1992

[23] C. Romessis, K. Mathioudakis, "Bayesian Network Approach for Gas Path Fault Diagnosis," ASME. J. Eng. Gas Turbines Power, Vol. 128, No. 1, 2004, pp. 64-72

[24] T. Kobayashi, D. L. Simon, “Aircraft Engine On-Line Diagnostics through Dual-Channel Sensor Measurements: Development of an Enhanced System," In Proceedings of ASME Turbo Expo 2008, Berlin, Germany, 913 June 2008, NASA/TM-2008-215229

[25] L. Nyulászi, R. Andoga, P. Butka, V. Gašpar, "Comparison of Experimental Identification Methods Using Measured Data from a Turbojet Engine," in SAMI 2016, 2016, pp. 23-27, ISBN 978-1-4673-8739-2

[26] L. Ljung, "System Identification,” New Jersey: PTR Prentice Hall, 1987, 255 pp., ISBN 0-13-881640-9

[27] F. Adamcik, R. Bréda, P. Kurdel, V. Beno, "Modeling of Changes in Flow Air Fuel Effected by Changes in Environmental Conditions," NAŠE MORE: znanstveno-stručni časopis za more i pomorstvo, 61(1-2), 2014, pp. 40-42

[28] M. Rahmat, et al., „Accuracy Comparison of Arx and Anfis Model of an Electro-Hydraulic Actuator System," in International Journal on Smart Sensing and Intelligent Systems, Vol. 4, No. 3, 2011, pp. 440-453

[29] Selecting a Model Structure in the System Identification Process [online] Available on: 〈http://www.ni.com/white-paper/4028/en/>

[30] M. R. Soumya, S. Bidyadhar, G. Subhojit, "PI Controller Design for a Coupled Tank System Using LMI Approach: An Experimental Study," Journal of Chemical Engineering \& Process Technology, Vol. 7, No. 1, 2016, 8 pp., ISSN 2157-7048

[31] C. H. Chen, C. C. Chung, F. Chao, C. M. Lin, I. J. Rudas, "Intelligent Robust Control for Uncertain Nonlinear Multivariable Systems using Recurrent Cerebellar Model Neural Networks," Acta Polytechnica Hungarica, Vol. 12, No. 5, 2015, ISSN 1785-8860 
[32] Y. Kim, Y.-S. Kim, "Optimizing neural network to develop loitering detection scheme for intelligent video surveillance systems," International Journal of Artificial Intelligence, Vol. 15, No. 2, 2017, pp. 30-39

[33] B. Zhang, J. Lam, S. Xu, "Stability Analysis of Distributed Delay Neural Networks Based on Relaxed Lyapunov-Krasovskii Functionals," in IEEE Transactions on Neural Networks and Learning Systems, Vol. 26, No. 7, 2015, pp. 1480-1492

[34] Y. Gao, M. J. Er, "NARMAX time series model prediction: feedforward and recurrent fuzzy neural network approaches," Fuzzy Sets and Systems, Vol. 150, No. 2, 2005, pp. 331-350

[35] T. Lazar, L. Madarász, et al., "Vzájomnost' teoreticko-praktických problémov prognózovania spol'ahlivosti MPM (Mutuality of theoretical and practical prolems in reliability of small turbojet engine)," elfa, s.r.o. Košice, 2015, 275 pp., ISBN 978-80-8086-236-7

[36] R. Andoga, L. Főzo, L. Madarász, T. Karol', “A Digital Diagnostic System for a Small Turbojet Engine," Acta Polytechnica Hungarica, Vol. 10, No. 4, 2013, ISSN 1785-8860

[37] E. Kiyak, A. Kahvecioglu, F. Caliskan, "Aircraft Sensor and Actuator Fault Detection, Isolation, and Accommodation," in Journal of Aerospace Engineering, Vol. 24, No. 1, 2011, pp. 47-58

[38] Z. N. S. Vanin, N. Meskin, K. Khorasani, "Multiple-Model Sensor and Components Fault Diagnosis in Gas Turbine Engines Using Autoassociative Neural Networks," in Journal of Engineering for Gas Turbines and Power, Vol. 136, No. 9, 2014, p. 16

[39] E. Tóth-Laufer, M. Takács, I. J. Rudas, "Fuzzy Logic-based Risk Assessment Framework to Evaluate Physiological Parameters," Acta Polytechnica Hungarica, Vol. 12, No. 2, 2015, ISSN 1785-8860 